\title{
Analysing the Impact of Regulation on Disruptive Innovations: The Case of Wireless Technology
}

\author{
Dmitrii Trubnikov ${ }^{1,2}$
}

Received: 12 September 2016 / Revised: 26 November 2016 /

Accepted: 21 December 2016 / Published online: 4 January 2017

(C) The Author(s) 2016. This article is published with open access at Springerlink.com

\begin{abstract}
The paper analyses the role of regulation in the suppression of disruptive innovations and shows that this process might be explained by the dependance on the path of joint evolution of regulation and the mainstream technology. Industrial policy in highly regulated industries such as wireless telecommunications is able to support evolution of established technologies and adjust itself to sustaining innovations, while regulatory disconnection impedes disruptive technologies, and the market plays a quite secondary role in this process. We observe more innovations in those parts of telecommunications where regulator is less active, but the core, the physical layer, of the industry is changing in sustaining way of development of the technology. The paper argues that the problem of impediment to disruptive innovations could be alleviated if the crucial resources of the industry were accessible for a number of potential innovators and newcomers. The openness makes easier the appearance of disruptive technologies, and regulation must facilitate it in order to promote opportunities for creative destruction.
\end{abstract}

Keywords Disruptive innovations · Wireless technology $\cdot$ Telecommunications · Regulation · Competition

JEL classification $\mathrm{O} 3 \cdot \mathrm{L} 96 \cdot \mathrm{L} 52$

\section{Introduction}

Despite the different views in Economics on the relationships between innovation and competition, some aspects seem pretty obvious and even trivial. The best incentives for innovation activity is the "the difference in profit that a firm can earn ... compared to what

Dmitrii Trubnikov

d.trubnikov@uvt.nl

1 Tilburg Institute for Law, Technology, and Society (TILT), Tilburg University, Tilburg,

The Netherlands

2 CIRSFID, University of Bologna, Bologna, Italy 
it would earn" otherwise (Gilbert 2006). Opportunity to escape competition and gain a monopoly and, thus, to charge prices higher than the competitive level is one of the main driving forces of innovations. ${ }^{1}$ Therefore, the conduct of a company that innovates is anticompetitive by its nature, but it does not mean that such behaviour is undesirable from the point of view of social interests and, thus, is not considered in such a way by antitrust policy. ${ }^{2}$ What is really desirable is that competitors of the innovator also have opportunities to innovate and positively affect the innovative conduct of the leader. However, at this particular point the triviality of the problem disappears and we enter the field of different legal and economics concepts, tools and methods of dealing with issues related to allocation of exclusive privileges and antitrust investigations.

The understanding that the aspiration of monopoly is the best incentive for innovation has moved the economics mainstream to the promotion of the idea that there are needs for government interventions that would provide exclusive rights for innovators. However, we can hypothesise that the market per se could be sufficient to the promotion of incentives for innovators $^{3}$ and, at the same time, could, possibly, make obsolete any needs to antitrust interventions. Therefore, it is quite risky to make conclusions that reasons for the victory of the leaders are their best business practices without paying attention to the fact that regulation played certain role in this superiority.

For instance, antitrust authorities might investigate the conduct of a company that had, allegedly, abused their intellectual property rights, inducing the discussion about the validity of such suspicion, but they can not affect the core of the problem, since the privileges to exclude others are precisely the main intention of the institution of intellectual property. They can be trying to assess the potential harm to consumers after a merger of some significant market players, but it is difficult to take into consideration that the structure of this market had been already transformed to the oligopolistic form by the regulatory policy and the real market forces have not already played a noticeable role in the field. Dogan and Lemley (2008) notice these shortcomings of antitrust law when they point out that "threats to competition do not come only from private conduct in unregulated industries, ... [but] also come from government regulation itself. ... Where it is the state itself that decides upon an anticompetitive end, the antitrust laws have not intervened."

Meanwhile, the problem becomes more complicated when the task of antitrust investigation is not only to develop the theory of harm to consumers, but to understand how the opportunities of market participants for innovations might be harmed. ${ }^{4}$ However, it should be noticed that innovations very often come to our life in completely unpredictable ways, and, thus, it might be merely impossible to assess the potential harm for innovations if even the source of such unpredictable innovations is uncertain. What is more important is that the real threat for innovations comes not only from the conduct of leaders, but from the legal frameworks that determine such conduct and protect positions of incumbents.

\footnotetext{
${ }^{1}$ Such arguments are very common in the justification of the institution of intellectual property. See, e.g., Posner (2005).

${ }^{2}$ Shelanski (2013), for example, notices that "Innovation inevitably leaves some firms behind and may confer market power on the innovating firm. ... innovation greatly benefits consumers and should not be viewed as any more harmful to competition than when a firm cuts price and thereby leaves its rivals without customers".

${ }^{3}$ Fritz Machlup (1958), commissioned by Congress of the United States to evaluate the country's patent system, concluded that "If we did not have a patent system, it would be irresponsible, on the basis of our present knowledge of its economic consequences, to recommend instituting one. But since we have had a patent system for a long time, it would be irresponsible, on the basis of our present knowledge, to recommend abolishing it." ${ }^{4}$ Some scholars pointed out that "[t]his calls for innovative theories of harm" (De Streel and Larouche 2015).
} 
One of the popular theories dedicated to innovations that appeared in the middle of the 1990s (Bower and Christensen 1995), and since that time has been embraced by many scholars, claims that "leading firms almost always triumphed in battles of sustaining innovation and that entrant firms typically beat the incumbent leaders when disruptive innovations emerged" (Christensen 2006). Disruptive innovation is one of those forces that can yield the real threats to established firms and "generates the kind of 'creative destruction' described by Schumpeter" (De Streel and Larouche 2015). Shelanski (2013) points out that due to the importance of creative destruction, the Schumpeterian approach, despite its arguments about the negative relation between competition and innovations, does not exclude antitrust interventions in the regulatory policy. ${ }^{5}$

Meanwhile, for established firms the best way to protect their positions is to capture the control over innovations, and here both kinds of innovations, sustaining and disruptive, are equally important to be controlled. In highly regulated industries, such as telecommunications, the "anticompetitive end" might be the result of regulatory activity, and the opportunities for disruptive innovations might be harmed by regulation.

Since the source of the disruptiveness is not always certain, the possible response to the attempts to control the development and innovations in telecommunications industry is the placement of the crucial resources of the field in the realm of "commons". Lawrence Lessig (2001) uses the similar idea when he talks about the control over the physical layer of a communications system. The problem is that the most of them by their economic nature are classic examples of private goods, since they are both rivalrous and excludable. Possibly, we could base some hypothesis on the enormous potential of the capacity of fiber-optic infrastructure, but since the access to this infrastructure has physical barriers, its exploitation in the way of an uncontrolled "physical layer" seems difficult. At the same time, the radio spectrum by its nature is "common good", and it is quite possible that technological solutions might alleviate the problem of the rivalry of this good, and, thereby, transform it into the economic realm of "public goods". Another crucial resource of telecommunications, that is also by its nature is non-rivalrous and non-excludable, is information and knowledge that are controlled by the incumbents through the institution of intellectual property. It is possible to assume that the mechanisms of control over these resources maintain the oligopolistic structure of the field and facilitate the development of the mainstream part of the industry.

The purpose of this paper is to highlight the role of regulation in the suppression of disruptive innovations in telecommunications and to show that this process is explained not mainly by explicit actions of government in the interests of incumbents, but rather by the dependance on the path of joint evolution of regulation and the mainstream technology. In the beginning of the paper, I provide a brief analysis of disruptive innovations in telecommunications and distinguish WiMAX as a real life example of disruptive technology in the industry, explain this position and describe the economic model of the technology. Then I use this case to demonstrate that the failure of this disruption was determined by state interventions in market mechanisms that, eventually, did not allow to put into practice the economic model, and protected the established status quo of the area. In the final section I argue that the current paradigm, that justifies regulatory interventions, heavily depends on the previous way of

\footnotetext{
${ }^{5}$ Shelanski (2013) claims that "[a] natural implication of the Schumpeterian argument is that a firm with market power would ... have an incentive to interfere with the cycle of "creative destruction" by impeding rivals' ability to develop new products or services that threaten its dominance."
} 
interaction of regulation and technology, and it locks the evolution of the industry on the mainstream technology, protecting business interests of incumbents.

\section{The Disruptiveness in Wireless Communications}

\subsection{Disruptive Innovations in Telecommunications}

According to the concept introduced by Christiansen and Bower in 1995, innovations could be classified on sustaining, when innovations take place within the existing market and "tend to maintain a rate of improvement [providing] customers something more or better in the attributes they already value", and disruptive, when innovations "introduce a very different package of attributes from the one mainstream customers historically value". The initial version of the concept claimed that in the first phase an innovation performs worse than the main product or services in the market but with lower prices, and only in the second phase, the quality of the innovation increases and attracts the mainstream consumers. However, in more general view, a disruption comes not only from the "low end", but also from the "high end" (Govindarajan and Kopalle 2006) and from a "new market" (Christensen and Raynor 2003), and it might be claimed that one of the core features of disruptive innovations is their financial unattractiveness for the incumbents (Christensen 2006).

We can find some noticeable examples of disruptive innovations in the telecommunications industry: Skype that has gained the benefits of the market of long-voice telephony, numerous Internet messengers, that partly substituted SMS services or even traditional voice services, or Internet video streaming services such as NetFlix. However, the majority of these examples shares one distinctive feature that, in general, does not entirely fit the concept of disruptive technologies: entering the telecommunications market from the outside they have not undermined the positions of the incumbents of the industry.

Indeed, from this point of view these innovations of telecommunications services differ significantly from other examples of disruptiveness. The appearance of smartphones subverted the market of mobile phones and destroyed the business of the former leader of the market Nokia. The introduction of digital photo cameras ruined the business of Kodak. At the same time, the appearance of Skype, despite of the undeniable significance of the innovation for the industry, has not destroyed the business of British Telecom, Deutsche Telecom or Telefonica. There are some concerns of the incumbents about "commodization" of their services (Larouche 2007; Kushida 2015), but it does not mean the loss of their places under the sun.

The reasons for sustainability of the established players of telecommunications towards such kind of disruptive innovations are pretty apparent - these innovations did not attack the infrastructure layer of the industry. They have changed the structure and the models of the business of incumbents, substituting voice or video traffic by data traffic, but not their positions. We can also notice that they broadened the borders of the industry and triggered competition on some of its layers, but did not challenge the core. Moreover, even appearance of many of these innovations was determined by the development of this core and their commercial success was merely impossible before the infrastructure layer reached conditions that allowed their proliferation.

However, even the infrastructure layer of the industry can also be challenged, and history shows us the case when the landscape of telecommunications could have been changed by 
disruptive wireless technology. From this point of view, WiMAX ${ }^{6}$ might be to some extent considered as an attempt to construct an alternative infrastructure apart from the mainstream industry that could help to form an open and competitive environment in telecommunications.

Nowadays the story of WiMAX has already almost evaporated from the discussions of telecommunications researchers and many of the main actors of this scene even disappeared from the list of active players of the field (Alvarion, Redline, Aperto Networks, Airspan, etc.). Nevertheless, it is impossible to deny that, firstly, this story has had a significant value for development of the field. Secondly, the entire project cost a lot for the participants and, possibly, might be considered as one of the most costly undertakings that has ever existed in telecommunications and has not achieved success. Only Intel alone invested a huge amount in this idea, and that money was spent not only on R\&D or production of WiMAX chipsets, but also on the deployment of wireless networks ${ }^{7}$ and even acquisition of radio frequencies (PCWorld, May 8, 2008). By 2011 there were deployed more than 500 WiMAX networks worldwide (Financial Times, August 16, 2010), and vendors of consumers electronics supplied their devices with WiMAX chipsets inside. ${ }^{8}$ Finally, this case might represent an interest for the empirical studies dedicated to the analysis of the impact that regulation has on development of technology, and to the analysis of the intersection of regulation and market mechanisms, that exposes that technological superiority or even first-mover advantage are not necessary conditions for the victory in the competitive environment in the presence of regulation.

\subsection{The Strategic Inflection Point in Telecommunications Industry}

The theory of disruptive innovations initially appeared in management science (Bower and Christensen 1995) and then was adopted by researchers of other areas of social sciences. Similar ideas can be found in papers of Andrew S. Grove, who was among the chief executives of Intel Corporation from the time of the creation of the company, and it makes a particular sense for the purpose of this article, since this company is one of the main actors of the story. In his works dedicated to management, Grove introduced the concept of "strategic inflection point" that is trying to describe a situation "when a major change takes place in [the firm's] competitive environment" and requires "a fundamental change in business strategy" (Grove 1998).

The end of the XX century and the beginning of the XXI century might be considered as a "strategic inflection point" for many companies whose main business was in the fields of the new economy. Even those companies whose market positions seemed sustainable for the outer

\footnotetext{
${ }^{6}$ For the purpose of this article the term WiMAX, that is an acronym for Worldwide Interoperability for Microwave Access, is used to refer to the IEEE 802.16 standard for wireless metropolitan area networks. The terms "WiMAX technology" or "WiMAX standard" in this paper describe the technology that complied with the sub-sets of IEEE 802.16 standard approved by the WiMAX Forum, the organisation that promoted the concept and coordinated certification of compliance with IEEE 802.16 and interoperability.

${ }^{7}$ The most noticeable example is Clearwire where the company lost about 1 billion according to its Preliminary Fourth-Quarter Financial Information published on 7 January 2009 (Available at http://www.intc. com/releasedetail.cfm?ReleaseID=357860), but there were also Orascom Telecom in Egypt, Worldmax in the Netherlands, PIPEX Wireless in the United Kingdom, Unwired in Australia, Neovia in Brazil, etc. (Intel News Release, May 22, 2006. Available at http://www.intel.com/pressroom/archive/releases/2006/20060522corp.htm). ${ }^{8}$ For example, in the list of WiMAX Certified products that were approved for the usage in the WiMAX network of Japaness company UQ Communication there are laptops and tablets produced by Lenovo, Acer, Sony, Panasonic, Toshiba, Fujitsu, etc. Information available at the website of the company http://www.uqwimax. jp/english/annai/certification/info.html
} 
threats were under the risk to lose their business if their markets lose their attractiveness for consumers due to the technological advances and appearance of new solutions for the problems of human beings. The digital technologies of the XXI century provided opportunities for such disruptiveness and left entire markets in the annals of history. Examples are markets of tape recorders and cassette tapes, analog photo cameras and photographic films, cable radio, matrix printers, cathode ray tube technology, etc. Meanwhile, not only the digital world threatened positions of companies that achieved their success in the XX century - the development of digital technologies also threatened the status quo of the digital marketplace. Grove (1996) pointed out that Intel, whose main business was production of dynamic memory chips and who was one of the leaders of this market, in the middle of the 1980s had a real risk to lose everything and only the decision to change the business and to move the focus on manufacturing microprocessors allowed the company to protect its positions and to reach worldwide leadership in the growing market of personal computers.

The threat to the positions of a company comes not only from the industry where it is active, but also from external markets, and in the case of personal computers, the threat could be expected, and now we observe its materialisation, from mobile devices. From the beginning of its appearance, the mobile phone has been more and more transforming to a device with computational capacity that allows to execute a big variety of different tasks. Modern tablet PC already might be considered as a real substitution for traditional personal computers, ${ }^{9}$ but the main players of the market of components for these mobile devices are not the same as were in the market of components for personal computers. The growing industry of mobile devices has been the real, albeit long-term, disruptive innovation for the established industry of personal computers, and the top-managers of the incumbents of the latter at the turn of the centuries could already understand it, and, moreover, it could be quite tempting for them to extend their business to the new area.

Meanwhile, to become a leader of the new field was not easy even for such giants as Intel Corporation. The incumbents of this market controlled the field through numerous patents for the essential technologies. Qualcomm in 2000 was already "emerging as a kind of Intel of the wireless era" (FORTUNE Magazine, May 15, 2000), and ARM Holdings, that licensed its processor designs to other chip-makers including Qualcomm, Apple, Samsung and others, has become a sort of standard in the growing industry of chipsets for mobile devices. We can find figures that show that in 2006 about $98 \%$ of all mobile phones already used ARM solutions on their motherboards, and, moreover, the company had plans to extend its business and to become "the architecture for the digital world" (CNET, April 3, 2006).

The alternative to the entry to this field could be creation of a new technology and a new market based on this technology, that would be able to substitute the next stage of the current way of development of the industry. Therefore, the task could be to find ways for the creation of this market and alteration of the trajectory of the development of the industry towards the new technology. In other words, the task was creation of a disruptive technology for telecommunications in general. In order to protect its positions in the entire semiconductors industry where growing market of mobile devices threatened the established order, such companies as Intel had to introduce their own disruptive innovation for the new field.

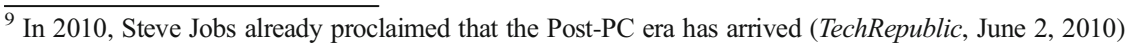




\subsection{The Disruptiveness in Different Layers of Telecommunications and the Economic Model of the Wireless Innovation}

In general, WiMAX was not the only example of wireless technologies that could threaten the established telecommunications business at that time. ${ }^{10}$ Moreover, we can find information that before taking the leadership in the WiMAX Forum, Intel executives also considered the alternatives, but finally stopped their choice on the technology, because they saw that "only WiMAX drove the technology with economic model" (Fitchard 2008).

When Intel took the leadership in the WiMAX Forum, the concept of the technology had been transformed from "an access alternative", that aimed to be as a wireless solution for the last mile problem, to "a platform for mobile computing" (Fitchard 2008). The way of the development of telecommunications industry traditionally had in its core voice services, while data transfer had been gradually added to the technology. The opportunity for disruptiveness was to turn it upside down and to put the data transfer in the core of the system, while voice services could be just a part among other opportunities provided by the technology. ${ }^{11}$

Meanwhile, WiMAX was not an innovation that could be brought to the market with efforts of just one creative company, it was a concept that threatened the status quo of different markets and assumed joint actions of many players from various layers of telecommunications. The result of these actions could be expressed in alteration of all of these markets, formation of new business models and creation of new leaders. If Intel was seeking the ways to extend its semiconductor business in the new area, there were players in other fields that understood their possible benefits from new markets that could be created by the technology.

From the perspective of telecommunications business, WiMAX was not attractive for incumbents of the mobile industry, especially for those who already invested in the creation of $3 \mathrm{G}$ infrastructure (Conti 2005). WiMAX did not assume the evolution of the networks of mobile providers, but instead required new investments in the creation of new networks that would operate separately from the cellular networks. Of course, some core parts of the networks infrastructure might be used for different kinds of networks, but, nevertheless, the adoption of WiMAX for mobile carriers could signify excessive investments in the equipment without returns from the previous undertakings (Weil 2009, 9). In other words, sunk costs associated with their current way of development made adoption of the non-mainstream innovation highly unattractive to their business models. From this point of view this technology perfectly fits one of the important features of disruptive innovations that was noticed by Christiansen and was highlighted in the beginning of this paper, namely, the financial unattractiveness for incumbents. However, it does not entirely mean that mobile service providers would never develop WiMAX networks. In order to preserve their positions and to broaden the spectrum of services they could not entirely reject WiMAX technology, but they were reluctant in their response to the emergence of this innovation and it was, definitely, not the best way of the development of the industry for their business models. ${ }^{12}$

\footnotetext{
${ }^{10}$ We also can notice Mobile Broadband Wireless Access specification IEEE 802.20 or other subsets of IEEE 802.16 such as WiBro.

${ }^{11}$ Intel fellow and CTO of Intel's wireless group Siavash Alamouti described these Intel's attempts to enter the wireless market in the following way: "...this is not an Intel-versus-the-wireless-industry situation... [but] the computing and electronic industry versus a telecom industry traditionally dominated by voice". (Fitchard 2008). 12 Moreover, even for the incumbents of the mobile world WiMAX still could be interesting as a strategy for entry in the new territories, and, as a result, we can find examples of deployment of WiMAX networks by the world leaders of mobile communications. For instance, there were networks of Vodafone under the brand Vodacom and the former French monopoly Orange in some African countries, but, again, it rather show the possibility of the usage of the technology for disruption of existing or creation of new markets.
} 
The technology was not only unattractive for the established mobile operators, but also for the incumbents of the traditional wired telecommunications industry. Many of them already had assets in the mobile business and, thus, there were no reasons to create competition with other units within their companies. Reasons for the adoption of fixed WiMAX solutions were even weaker than the possible embracement of the mobile version of the technology: the implementation of fixed WiMAX for remote areas might be less attractive business than the monopolistic development of wired infrastructure through the government subsidisation of the universal service, while creation of such networks in parallel with their existing networks simply made no sense.

Meanwhile, by the middle of 2010 the total number of deployment of WiMAX networks reached 500 in 147 countries (Financial Times, August 16, 2010). In some of these cases it was an attempt of provision of mobile services, but in many it was competition with incumbents of wired telecommunications and even a natural solution of the digital divide problem. ${ }^{13}$ WiMAX, despite of its unattractiveness for established players of the field, opened doors for newcomers or helped to solve the "local loop" problem for those who otherwise had to rely on the incumbents' infrastructure.

In 2004, Intel executives claimed that WiMAX technology will "truly usher in the broadband wireless revolution" and saw three phases of the deployment of the technology: 1) outdoor solutions, 2) indoor solutions, 3) mobility (Intel News Release, Jan. 21, 2004). This three-phases evolution approach was included in the plans of certification of WiMAX equipment, and there were proposals that this upgrade on the higher phases might be done through the installation of new versions of software, while the hard core of the network would remain the same. The third mobile phase of the technology was later considered as one of the possible versions of $4 \mathrm{G}$ mobile telecommunications, however, this candidate for $4 \mathrm{G}$ was not an evolutionary path of the mobile technology, but the mobile version of the fixed wireless technology.

There were several issues for those who considered to invest in this sort of business, and the economic model of WiMAX had to have a solution for these problems in order to find widespread adoption. First of all, the price of the network equipment and end-users terminals had to be significantly lower than those provided by competing technologies, and in different phases of the development of the technology different alternatives could be considered as rivals.

Secondly, there was a necessity to avoid the high costs of installation of end-users equipment, and it was an issue in the first two steps of the development of the technology, that were based only on the solutions for the fixed broadband access.

Thirdly, the technology must provide a cost-effective solution for the architecture of the network in the sense of the coverage area of a base station and required number of the base stations. It should take into account such aspects as the absence of a line of sight between base stations and end-users terminals and the necessity to arrange high speeds connections.

Then, there should be a solution for the network infrastructure. The technology allowed to solve the problem of the last mile, but it was not less important to understand how the core of the network could be connected with other network elements and, moreover, how it could be interconnected with other networks. This task could not be solved solely by technological means, and required active participation of government in the promotion of development of

\footnotetext{
${ }^{13}$ Some even considered WiMAX as a possible "cost effective solution to answering the challenges posed by the digital divide". (Yarali et al. 2007).
} 
infrastructure and competition in this area. It was already clear by the time of the appearance of WiMAX that "[s]uccessful competition for infrastructure can reduce the needs for access regulation" (Canoy et al. 2003, 71). At the same time, the European approach that aimed to the promotion of service-based competition was not the best solution for infrastructure development and some recent researches point out these shortcomings of European regulation (Yoo 2014). ${ }^{14}$

Finally, maybe the most important issue that had to be solved for the attraction of investors and entrepreneurs is the creation of expectations that this technology will change the world of telecommunications. Investments in the creation of WiMAX networks for the provision of services in underserved areas could be a question for new adepts of the technology, but if to consider the outdoor solutions for the coverage of these areas as just a first stage in the formation of the future mobile business, then this activity is merely a necessary part of the whole business model where the desired pay-off will be achieved later.

The leadership of such company as Intel in this project was a noticeable signal about the commitments of serious players towards the technology. Mo Shakouri, who was a vice president of WiMAX Forum, pointed out that "without Intel's support the WiMAX industry never would have moved so fast" (Fitchard 2008), and this speed of the development of the project increased expectations of investors. In September 2007, Intel's WiMAX plans were more than ambitious: 150 million subscribers worldwide one year later in 2008; 750 million, more than $10 \%$ of the world population, in 2010; and 1.3 billion in 2012 (Gardiner 2007). Paul Otellini, CEO of Intel of that time, claimed that the industry is moving toward ultra mobility and "WiMAX ... will be the network that provides that" (Gardiner 2007).

To summarise, the success of the technology required its widespread adoption that could be achieved through interoperability, solution of the cost-effective network architecture issue, provision of expectations of the future alternative telecommunications market and assistance of governments in the creation of the backbone infrastructure, and would allow to decrease the prices of equipment and to eliminate the costs of installation. At the same time, these tasks were highly complicated by the issues of the allocation of radio frequencies and by the industrial policy, and, moreover, the failure in the finding of the solution for these problems merely signified that the primary goals would not also be achieved.

\section{The Role of Regulation in the Development of Wireless Industry}

Technological change is not an independent process as it is assumed by technological determinism, and the market is not the only social institution that influences technology (MacKenzie and Wajcman 1999). Regulation co-determines the development of technologies and even technologies that will be embraced by society, as well as technologies that would be thrown away from the main course of technological development. Butenko and Larouche (2015), for example, argue that "regulation affects which inventions are made, which are developed, and which are not, as well as which take off, and which do not". The interaction of technological change and regulation defines the actions of industry players and shape the architecture of the network and characteristics of the key technologies, and telecommunications provide us good examples of how "all changes in regulation produce important

\footnotetext{
${ }^{14}$ For the discussion about advantages of facilities-based competition see also Lemstra et al. (2015), De Bijl (2005).
} 
consequences on the organization of the industry that in turn ... have important consequences on the technology" (Antonelli 1995). What is more interesting here and what might be referred from the case of the WiMAX story is that in the current regulatory regime the market plays a quite secondary role in this process. The victory in the battle between the evolution of the mainstream technology and the disruptive technology proposed to the market from the outside was not determined by the superiority of technological solutions or even more sustainable business models of the established players, but was a consequence of regulatory decisions and legal norms in some key aspects. Eventually, the economic model of WiMAX could not solve the problems highlighted in the previous section and there is a clear relationship between this failure and the government interventions into the market.

Indeed, among the studies dedicated to the comparison of mobile WiMAX and LTE we can find that LTE did not have technological superiority ${ }^{15}$ and, thus, earlier WiMAX appearance in the market could have played as a first-mover advantage. The business models of the mainstream operators could be threatened by the appearance of newcomers, but chances to succeed in the telecommunications marketplace for those who were eager to launch the new wireless business were significantly affected by the regulation of the field.

The deployment of wireless networks heavily depends on the ability of telecommunications operators to get radio resources. Only very limited parts of the radio spectrum through out the world are accessible on the free basis, while mostly commercially interesting radio resources are under the control of governments everywhere, and, moreover, these resources have not been available for "two guys in a garage" 16 who could have brought the disruption into the markets of telecommunication services. On the contrary, the social utility from the economies of scale, and understanding of the best ways of its achievement incorporated in the economics mainstream, have always ruled the decision makings concerning the radio spectrum allocation, and instead of distribution of the radio spectrum for a number of entrepreneurs, it has always been allocated to small groups of big service providers. ${ }^{17}$

There is also another area of government interventions, that is very relevant to the field of wireless technology, as well as to the industries of the new economy in general, and this area is the institution of intellectual property. As it was mentioned in the beginning of the paper there is no consensus about the scope of necessary interventions and even a necessity to create incentives through the provision of exclusive rights. This section of the paper analyses the impact of both of these aspects, the government intervention in the area of radio spectrum use and allocation of exclusive rights to objects of the intellectual sphere on the eventual defeat of the disruptive wireless technology by the mainstream part of the industry, and, at the same time, discusses the possible positive role of regulation in the promotion of technological pluralism in the industry.

\subsection{Radio Spectrum Allocation}

One of the main aspects of the legal frameworks that has always influenced the development of the industry is regulation of the radio spectrum, and this is not limited to the market of telecommunications services, but also affects the market of manufacturers. The problem is not

\footnotetext{
$\overline{15}$ Some even claims, that WiMAX performed better in some cases (Roodaki et al. 2014).

${ }^{16}$ The term here is adopted from Christensen et al. (2013), who notice that "Disruptive innovations are ... products or services, often created by "two guys in a garage"."

${ }^{17}$ Melody (2012), for example, notices that in the EU "[t]he liberalisation objective of stimulating competition and opening access apparently was not considered to be the cornerstone of spectrum policy".
} 
only that the state allocates rights to use radio waves, but it also determines how the spectrum should be used, and this particular issue makes innovation dependent also on policymakers, but not only on creative minds. ${ }^{18}$

The developers of the WiMAX standard from the very beginning had been struggling with the necessity to comply with spectrum regulation that was different in different places and, thus, availability of the parts of the spectrum for the future deployment of networks was also different. For example, the report of the OECD (2006) pointed that "Much of the success of WiMAX hinges on the ability of operators to find appropriate and available spectrum", and that "without a globally recognized frequency band, the economies of scale will be reduced". It was also clearly understood by the members of WiMAX Forum and was expressed in its official papers dedicated to the regulatory issues (WiMAX Forum 2004). ${ }^{19}$ Furthermore, the developers, in order to mitigate the problem and to find some intersections in the regulation of spectrum in different countries, were trying to adjust technical features of the technology to these common points by reducing, for example, the required bandwidth for a channel or the transmission power. However, at the same time, it limited the capacity of the technology.

Even in the $3.5 \mathrm{GHz}$ band the regulation of some countries (e.g., Sweden or the UK) directly prohibited mobility of telecommunications services "other than 3G services" (OECD 2006, 21). Therefore, while in the higher band $(5.7 \mathrm{GHz})$ mobility was limited by the laws of nature, in the band 3.5 GHz there was allowed only the competition with DSL due to the legal rules. In some jurisdictions there were restrictions on the coverage area of base stations that reduced the benefits of the cost-efficiency of the network infrastructure. ${ }^{20}$ Regulation of the usage of radio spectrum in several countries prohibited real mobility in wireless broadband networks, restricting the speed of end-user devices of such networks to the speed of pedestrians (OECD 2006). Moreover, the most suitable radio band for the mobility of WiMAX specifications, $2.5 \mathrm{GHz}$, was reserved for the evolution of the mainstream technology by the International Telecommunications Union, an agency of the United Nations, under the IMT-2000 umbrella, and, thus, could not be used in many of the world countries before the inclusion of WiMAX in the IMT-2000 family (OECD 2006).

The future rules were not determined and were unclear for those who considered to play this game, and, thus, increased risks of such investments. At the same time, for those who already had their business within the established order, such uncertainty was not a problem they had time to wait, to lobby their interests and to adjust their networks to the sustaining innovations of the mainstream technology. Even the disruptiveness of the technology could not provide enough incentives for investors if the future of the regulatory attitude towards the use of radio frequencies was so uncertain. The unclear situation with the possibility to use lower parts of radio spectrum (e.g. $2.5 \mathrm{GHz}$ ) on the third mobile phase of the technology significantly reduced the attractiveness of projects related to the first fixed phases for the potential investors.

About all factors of the success of the technology highlighted in the previous section heavily depended on the decisions of policymakers: the price of technological solutions

\footnotetext{
${ }_{18}$ The concept of technology neutrality is able to some extent alleviate the problem, but this principle was widely adopted by the industrial policy only after the mainstream of wireless technology defeated the main competitor, which at that moment was WiMAX.

${ }^{19}$ The paper notices "the uniform allocation of spectrum worldwide, is crucial to lowering equipment costs because radios are a major cost component in developing WiMAX Forum Certified systems".

${ }^{20}$ For example, in Russia the coverage area of WiMAX base station in the $3.5 \mathrm{GHz}$ radio band was restricted to $3 \mathrm{~km}$ with the maximum power of radio transmitter $-10 \mathrm{dBW}$. The same maximum power of radio transmitter was established for Wi-Fi (Decision of GRFC 28.11.05 № 05-10-01-001), and compliance with such rule merely made the economy of such networks quite doubtful.
} 
required economies of scale that could not be achieved without global adoption of the standard, the limitations imposed on the usage of wireless networks affected the costefficient architecture and the costs of installation, the uncertainty and the restrictive policies on the mobility decreased the expectations. Even solution of the problems of interconnections and backbones in many places of the world required government assistance and could not be solved independently from incumbents. In countries with a low level of concentration in the industry, with advanced fiber-optic infrastructure that was not totally under the control of incumbents and where there were possibility for its costs-efficient construction, like in Russia, the main problem to the entrance to the wireless market was a solution of radio frequencies allocation problem, while in those countries where telecommunications infrastructure was just recently opened for competition or was under the total control of incumbents the problem of entrance was more complicated.

The WiMAX technology was unable to achieve global adoption, and the final stage of the life of the project began in 2010, when it already became apparent that the mobile version of the standard lost the battle with LTE. This period revealed some examples that show that expectations of those who invested in the WiMAX projects hoping to obtain in the future the broader parts of radio spectrum and to extend their services were wrong. Dutch company WorldMAX $^{21}$ was forced to shutdown its WiMAX network in June 2010 because the government, in excuse of national security, put restriction on the license of the company regarding the usage of radio spectrum (Vos 2010). Just one month before, the company Freedom $4^{22}$ left the market of telecommunications services in the UK because the regulatory policy did not permit provision of mobile services on the WiMAX network of the company (Baker 2010). However, strictly speaking, mobility in the radio band $3.5 \mathrm{GHz}$ is limited also by economic rationales, but what is more relevant to the problem is that the company was also unable to get frequencies in the $2.6 \mathrm{GHz}$ radio band (Baker 2010).

The similar problem of impossibility to extend the radio resource of deployed fixed WiMAX networks into the radio band that allows mobility was observed in other parts of the World. The main explanation of this situation is that these radio resources were obtained by the mobile incumbents for the development of their networks, ${ }^{23}$ and for them, as described earlier, WiMAX was not the best alternative among WiMAX and LTE.

\subsection{Issues of Intellectual Property Related to the Wireless Technology}

As was noticed above, the economic model of the wireless technology requires a cost-effective network infrastructure. This could be achieved only if the technology incorporates the most advanced relevant technological achievements that existed in the industry at that time. In the world where ideas are not free and the owners of intellectual goods have rights to exclude others from the participation in the technological progress, the entities that were able to concentrate the rights on the most essential solutions for technological development have power to affect the total outcome of the industry. In the analysed case such "intellectual

\footnotetext{
${ }^{21}$ According to some estimations, Intel Capital and Enertel Holding jointly invested 37 million USD in the creation of this network in Amsterdam. (Higginbotham 2010)

22 This company was also the project with investments of Intel Capital (Intel News Release, Feb. 11, 2008)

${ }^{23}$ Possibly, the most noticeable exceptions from this pattern were Clearwire in the US and Yota in Russia, but in the second case the company gained frequencies and got opportunities to deploy networks in most of the Russian regions when WiMAX was already doomed and the company turned its efforts towards LTE.
} 
monopolists" 24 had very apparent interests in the promotion of the mainstream of the wireless telecommunications, rather than to allow disruptors to challenge their business positions.

Ericsson, the leader of the market of mobile networks equipment, joined the WiMAX Forum in 2004 (Ericsson Press Release, Dec. 13, 2004). The company has had "one of the industry's strongest intellectual property portfolios" (Ericsson Press Information, Feb. 2007), but has never been among the manufacturers of WiMAX equipment. Among those who were able to significantly benefit from the technology and who really produced certified WiMAX equipment were such companies as Alvarion, Airspan, Navini, Aperto Networks, etc. These companies might really be considered as outsiders of the market of wireless equipment and as disruptors of the established market. However, in the case of the victory of WiMAX in the competition for $4 \mathrm{G}$ standard they could get a portion of the pie. Some researchers argued that wide adoption of "WiMAX as a 4G standard would be crisis for Ericsson and Nokia Siemens Networks", and, as a result, these companies had to adjust their strategies to the promotion of LTE, and intellectual property rights could be a powerful tool for the achievement of such goal (Seo 2013, 169-171). In 2006 Ericsson terminated its participation in the WiMAX project and devoted its resources to HSPA and LTE. WiMAX was rather the threat than the opportunity for the company that controlled about the third of the mainstream market.

The most noticeable player in the sphere of mobile standards, Qualcomm, was also among those who had opportunities and incentives to determine the future of wireless technology, and, according to the claims of some experts, openly opposed the development of WiMAX (Bloomberg, September 3, 2007). In 2005, The Economist, describing the role of Qualcomm in the third generation wireless networks, claimed that "[b]ecause its technology underlies the third-generation mobile-phone standard, Qualcomm has become a toll bridge that all equipment-makers must cross" (The Economist, Oct. 20, 2005). In 2005 - 2006, Qualcomm significantly increased its patent portfolio concerning, inter alia, crucial solutions for WiMAX technology by the acquisition of the developer of MIMO technology ${ }^{25}$ Airgo and the pioneer and developer of OFDM technology ${ }^{26}$ Flarion, and became the holder of "the most widely licensed in the industry" patent portfolio that "applies to all existing 4G standards ... including ... LTE ... and ... WiMAX" (Qualcomm's LTE/WiMAX patent licensing statement, Dec. 2008). Some experts, commenting the acquisition of Flarion by Qualcomm, even claimed that "Qualcomm has now got its hands on all future mobile technology", and directly pointed out that, as a result of it, "WiMAX ... might face problems" (Lewan 2005). From the perspectives of disruptiveness of the mainstream wireless business for the market of traditional PC and WiMAX for the mainstream telecommunications, such actors of the semiconductors market as Qualcomm had clear reasons to be in favour of the wireless mainstream.

In order to help to promote the WiMAX technology in the middle of 2008 Intel jointly with Cisco, ${ }^{27}$ Samsung, Alcatel-Lucent and telecommunications service providers Sprint Nextel and Clearwire formed the patent pool Open Patent Association. The primary goal of the organisation was proclaimed "to foster a global ecosystem focused on delivering broader choice, competitive equipment and service costs for WiMAX technology, devices and applications". ${ }^{28}$ However, they did not manage to attract to this patent pool all companies that possessed the

\footnotetext{
${ }^{24}$ The term "intellectual monopoly" here is adopted from Boldrin and Levine (2008).

${ }^{25}$ MIMO is an essential element of many modern wireless standards.

${ }^{26}$ OFDM is a method of encoding digital data that has also found wide application in the wireless standards.

27 The company in 2007 for \$330 million acquired noticeable player among WiMAX manufacturers Navini Networks (FORTUNE Magazine, Oct. 23, 2007).

28 The website of the organisation is available through Internet archive https://web.archive. org/web/20110727151012/http://openpatentalliance.org/
} 
essential patents for the technology. The response of the mainstream industry was the commitments of the main patent holders "to a framework for establishing predictable and more transparent maximum aggregate costs for licensing intellectual property rights (IPR) that relate to 3GPP Long Term Evolution" (Ericsson Press Release, April 14, 2008).

Qualcomm did not join any of these agreements, but introduced in the same year their own FRAND patent statement. Qualcomm put it in the way that LTE and WiMAX "will be used to complement existing $3 \mathrm{G}$ deployments to help address the growing demand for mobile data", but the initial purpose of WiMAX was not the complementing of $3 \mathrm{G}$ deployments. The technological and logical continuation of $3 \mathrm{G}$ networks could be only LTE from these two alternatives, and it was clear for the senior executives of Qualcomm. Peter Lancia, Sr. Director in Marketing of Qualcomm, noticed that "LTE will provide a parallel evolution path to 3G, and will leverage 3G's scale and ecosystem of vendors, operators, consumers and application developers" (OnQ blog at the Qualcomm's website, May 25, 2010).

\subsection{Promotion of Competition and Technological Pluralism in the Industry}

Although the promotion of competition is among the priority goals of the industrial policy, the reality of modern days shows us that all layers of the industry have been becoming more and more concentrated, and this concentration takes place on the global level. By 2015, the major part of the market of mobile infrastructure equipment was already under the control of just four companies: Ericsson, Nokia, Alcatel-Lucent and Huawei, and nowadays, when Nokia finally gained control over Alcatel-Lucent, the oligopolistic structure has become even more prominent. The number of mobile service providers has also declined, and some European mobile markets have already changed their structure from four to three operators (Austria, Germany, Ireland, etc.).

The analysis of this paper is drawing the link between the regulation and the ongoing process of concentration of the industry, but this does not mean that in the pure laissez-faire system we would not face the similar problem or a set of other issues. As it was noticed above, the success of WiMax was practically impossible without assistance of governments in the creation of the backbone infrastructure and efficient solutions of the problem of interconnection. These crucial resources were under the control of incumbents, and for them the alternative development of the industry was not the best possible option, while new entrants, who could bring the disruption in the market, were in a dependent position from the conduct of the giants, and only industrial policy aimed at the promotion of technological pluralism and competition could alleviate the problem.

At the same time, if the aim of the competition policy is the promotion of competition between the main players, who already invested in development of the mainstream technology, but not facilitation of access for new entrants and opening doors for them for bringing new technologies, then we can hardly expect the appearance of innovations that threaten the mainstream course of the development due to the problem of sunk costs of the incumbents. Antonelli (1995) in his analysis of technological change in telecommunications points out that "the larger the variety of independent players, the larger the opportunities to generate new technologies", and it has a particular sense for the recent story of the wireless industry. There were a number of sets of $2 \mathrm{G}$ standards, then there were just two $3 \mathrm{G}$ sets of standards, and there is the only one standard considered as $4 \mathrm{G}$ technology. However, if the technological pluralism was a target of the industrial policy, then we could expect not only to have the diversity, but also to observe the continuing process of creative destruction in this viable field of the new economy. 


\section{The Mutual Shaping of Technology and Regulation in Telecommunications}

The regulation of telecommunications has evolved since the appearance of the industry, addressing its efforts to new issues that have been arising with the development of the technology. However, not only technology raises problems before policymakers and affects legal norms, but legal norms, in turn, affect the development of technology. In social sciences dedicated to regulatory issues this idea is expressed in the concept of mutual shaping of technology and society (e.g. MacKenzie and Wajcman 1999). Meanwhile, in a case of disruptive technology in highly regulated industries there could be an issue, because the law has been developing along with the mainstream of the industry and it has created the playground for the mainstream players, while for the technology that assumes an alternative way of the functioning of the field the old rules could be inappropriate or even hostile.

In other words, law and technology not only mutually shape each other, this mutual shaping process is able to form the high level of dependence on the previous way of development and protect the mainstream course of the technology from external threats. Many scholars point to the problem of "regulatory disconnection" (Brownsword and Goodwin 2012; Brownsword and Somsen 2009) or "pacing problem" (Marchant et al. 2011), the situation when the pace of development of technology is faster than of the law that aims to regulate this technology (Butenko and Larouche 2015). The WiMAX case shows us that industrial policy in highly regulated industries is able to adjust itself to sustaining technologies, even if with the time lag, while this disconnection impedes disruptive innovations. As a result, the incumbents of the field might even benefit from this pacing problem.

If, for example, there was no problem of interference, then there would not exist any need to solve this problem through regulation, but, at the same time, if this problem can be solved by means of legal tools and there are obvious beneficiaries of this mechanism, then the necessity to seek alternative ways of its solution is not so actual, unless it fits the aims of the main industry's actors. Moreover, even when technology is already able to provide such solution, and nowadays we can hear claims that this time has already come (e.g. Werbach 2004; Staple and Werbach 2004), the regulation is very reluctant to change its paradigm. The new technological paradigm might signify not only dramatic alteration of regulatory approaches without clear understanding of the final results, but also may have a significant negative impact on the business interests of current major players, and, thus, this regulatory shift is not desirable neither for the incumbents nor for the policymakers.

This is not only the case of radio spectrum or industrial policy of telecommunications in general. It is the pattern that can be found in many cases when a regulated industry faces disruptive innovations. Uber or Airbnb, for instance, have also experienced numerous obstructions from the side of regulation. ${ }^{29}$ However, the attempts of policymakers to protect the established business interests is not necessarily a case of regulatory capture, but also their natural response to the threats to stability, since new technology might convey unpredictable consequences.

It is also necessary to notice that some innovations, like, for example, implementation of BitTorrent protocol that has disrupted the copyright industry, or mentioned above Uber or Airbnb, have a crucial advantage compared to innovations in wireless telecommunications.

\footnotetext{
${ }^{29}$ One of the Wikipedia articles is even dedicated to the "Legal status of Uber's service". Airbnb also has the explicit opposition of regulation in many parts of the world: Canada (Montreal Gazette, April 29, 2015), Germany (Guardian, May 1, 2016), Russia (RBC, Oct. 8, 2015), and so on.
} 
They provide more opportunities for their users to disobey the law, and, thus, have more chances to success, while in the case of wireless technology the deployment of a network might require a high level of investments without the possibility to dissolve this activity in the ocean of other radio pirates, and that increases risks of potential "violators" and enhance the opportunity for law enforcement.

At the same time, the problem of impediment to disruptive innovations due to regulatory disconnection could be alleviated if the crucial resources of the field were accessible for a big number of potential newcomers. In the same way as the end-to-end principle of the Internet architecture facilitated growth of diverse online services (Lessig 2006), the physical layer of the industry could also make possible the appearance of new disruptive technologies and business models if the industrial policy were aimed to promote accessibility of the resources.

Of course, there is no shortage of justifications of limitations of freedom of potential radio spectrum users from the positions of public interests, but it is also necessary to notice that more and more scholars nowadays claim that if we take into account the modern technologies, then many of these assumptions are obsolete (see Werbach 2004; Staple and Werbach 2004; Milgrom et al. 2011). Moreover, the ideas that radio spectrum, or, at least, some of its parts, represents a common resource that should be returned to the realm of commons have become popular among many scholars (e.g. Benkler 2002; Lessig 2001; Werbach 2001). However, it is also possible to admit, that, on the one hand, this discussion about openness of radio spectrum could be quite futile without robust economic models that could drive innovations in this field providing numerous benefits for various strata of society, but, on the other hand, it is difficult to expect the appearance of such models without understanding the possibility of their implementation due to the total control of the resource in the interests of major players.

The idea of the open spectrum emerged before the appearance of WiMAX, and, indeed, the widespread implementation of this concept could become the significant part of the growing sharing economy. It is difficult to say now whether WiMAX or another wireless technology with the similar idea could really benefit from the openness of radio, but we can hypothesise that in this case this technology had more chances than the long term evolution of the mainstream. However, we can not truly say that WiMAX Forum aimed the efforts to promote the technology within the open spectrum concept, but the comparison with Wi-Fi, that mainly operates in the unlicensed frequencies, was one of the main parts of the leitmotif of the story (e.g. Intel News Release [Intel Outlines Broadband Wireless Vision], Jan. 21, 2004). Moreover, WiMAX camp considered the operation of WiMAX networks in the license-exempt parts of radio spectrum (Intel 2005). The license-exempt $5 \mathrm{GHz}$ band was among the "initial bands of focus" (WiMAX Forum 2004), but this radio band increases requirements of line of sight and, thereby, decreases the commercial attractiveness of the technology.

Meanwhile, innovations in the unlicensed parts of radio spectrum are able even to change the core assumptions of the mainstream economic models. For example, the phenomenon of community networks, where the infrastructure is a common-pool resource, hardly fits the mainstream understanding of the economics of telecommunications. Such networks provide services for dozens of thousands of subscribers and compete with the giants (Baig et al. 2015), but, again, one of the problems of their development is the access to the resources that are necessary for creation of this common infrastructure. However, if the scenario of the WiMAX camp about the widespread adoption of the technology and significant reduction of prices of WiMAX equipment was fulfilled, then this technology could be a powerful tool for such innovative business models. Moreover, the mesh topology of network architecture, that Benkler (2002) described in the model of the "Ideal Open Wireless Network", and that is 
widely used in the wireless community networks, was placed in the agenda of the evolution of WiMAX (Wei et al. 2005).

In the field of intellectual property WiMAX proponents promoted the idea about open patent system for the technology "[t]o help ensure product differentiation and interoperability at a more predictable cost" (Intel News Release, June 9, 2008), but they were not able to include in this pool the essential claims of the opposition of this technology, and again, it exposes the development of the mainstream institutions of our society that, even if unintentionally, protect the established status quo.

Although the institution of intellectual property and allocation of radio frequencies both represent the examples of government intervention in the mechanisms of the free market, they are quite different by their nature. In the case of radio spectrum distribution, the problem is based on physical characteristics of radio waves, that are expressed in the limitation imposed by the mother nature, while in the second case this is mainly an attempt to provide a utilitarian solution for economic issues, but not the problem imposed by the physical features of our world.

If we consider regulation as the institution that forms the common playground for different actors, then we might expect to see the difference between institution of intellectual property and norms of allocation of radio frequencies. Government establishes the same rules for all members of society to get protection on the results of creativity of human minds, and, theoretically, anyone can use these mechanisms for his business purposes. There is a restriction for the usage of a particular idea, but not the restriction for the use of alternatives. ${ }^{30}$ At the same time, the allocation of radio frequencies a priori does not assume the pluralistic landscape of commercial wireless networks and allows to allocate these privileges only to a very limited number of actors. However, it is possible to argue that this difference in some cases is mostly theoretical. Inventions might be essential for the entire industry without possibilities to invent around, ${ }^{31}$ and, thus, it could be an analogy between property rights on such resource and property rights on an essential part of the radio spectrum, merely because it might be an absence of alternatives in both cases. Since the technological inventions are not the result of individual genius but the natural consequence of technological development of our civilisation, ${ }^{32}$ even patent races to some extent might be considered as an analogy of "races" for radio frequencies, and, thus, both these institutions similarly promote the ongoing process of concentration of the field.

The optimal design of the institution of intellectual property in economics is often considered as a proper balance between provision of incentives for innovations and resulting monopoly prices and deadweight losses (See e.g. Merges 2000). However, the effect on prices is not the only economic effect generated by this institution, and some argue that we must weigh the benefits of IPR "against the costs of the centralization of economic decisionmaking and the creation of barriers to innovation and market entry" (Wu 2006). From this point of view, the most important economic effect of IPR is on industry structure and it reflects the idea that regulation, affecting the industry structure, also affects the architecture of the network. Centralisation of decision making about the technological development inevitably affects the process of technological change and expresses in the architecture of the network that is, as

\footnotetext{
${ }^{30}$ It leads some to the conclusion that "IP rights are rarely if ever "intellectual monopolies"." (Lemley 2009).

${ }^{31}$ Some even claim that "knowledge can be considered as an essential facility" (Antonelli 2007).

32 Such position is quite common, and, for example, can be found in Scotchmer (1991).
} 
Antonelli (1995) notices, "strongly influenced by the changing characteristics of clay technologies".

In their highly cited article of 1986 Sah and Stiglitz, analysing the process of decision making depending on architecture of an economic system, argue that, due to the imperfectness of decision making process and limited capabilities of human minds, polyarchical systems, whose architecture is represented by "a market oriented economy", provide more opportunities to accept "good" innovations, while in hierarchies, where decision making is centralised, the risk to sort out such projects is higher. At the same time, they claim that the advantage of hierarchical systems is that they better cope with Type II errors, when it would be more reasonable to reject some accepted projects. Tim Wu (2006) emphasises that since decentralised systems (polyarchies) are able to approve more projects than hierarchies, "they manage to capture the few available profitable ideas". Following the logic of this literature and taking into account that the technological variety of the wireless industry presented in the market is not so diverse, it is possible to argue that facilitation of decentralised decision makings in the industry would provide more chances for valuable ideas to materialise in the technological solutions.

Meanwhile, the decentralisation and pluralism are highly dependent on the institutional environment that, as it was highlighted above, requires active participation of the regulator. Access to radio frequencies, essential radio technologies, infrastructure and interconnection points are those issues which efficient solution, possibly, was able to change the course of the wireless industry. What is also interesting here, is that without regulatory participation in the solution of these issues even assured access to long term financial institutions, and in the WiMAX case we observe that Intel and others have invested a lot in the project, is not sufficient for the achieving success. Moreover, inability to get access to the industrial resources merely signifies that financial support of even a lucrative idea at an early stage of its development would be highly limited, and, again it plays as a discouraging factor for innovations in the field.

Nowadays, when intellectual property rights on wireless technologies have become more concentrated, when the most interesting parts of radio spectrum have already been assigned to the mainstream, and, moreover, when they already have been propertisized by the incumbents, the entire future of the industry is totally in the hands of these proprietaries - proprietaries of technology, infrastructure and radio waves, and we do not have robust reasons to assume that such a system is able to better appreciate potential innovations than an open and competitive marketplace. As it was mentioned in the beginning of the paper, this is not the problem of market concentration that could be solved by the implementation of antitrust, but this is the problem of the exclusive rights that were granted by regulation and that finally created the barriers for the appearance of any disruptions.

\section{Summary and Conclusions}

The analysed initiative to change the established wireless industry was totally defeated by the incumbents of the field. The industry has become more concentrated than it was 15 years ago, and this tendency is observed in all layers of telecommunications.

It is possible to draw some analogy of the WiMAX case with other cases of standard wars such as competition between Betamax and VHS. There were studies that claimed that Betamax was a superior standard, but, nevertheless, lost the battle, and, thus, it is possible to assume that 
the choice of the market did not represent the best possible outcome (Liebowitz and Margolis 1995). However, here is the crucial difference of these two cases. In the Betamax-VHS case the market played the superior role in the adoption of the technology, while in the WiMAXLTE case the role of the market was secondary and the outcome was mainly determined by regulation. Moreover, Sony, whose videotape format was defeated by JVC, was able to bring to the market the DVD format (in collaboration with Philips, Toshiba and Panasonic) and avoid the mistakes of the previous experience. The introduction of DVD was a clear disruption for VHS industry. The DVD format provided obvious advantages for participants of the home video market and, eventually, replaced VHS as a method of video distribution. On the one hand, these two examples show us, that the market does not exclude a risk to sort out superior technology and from this point of view it is impossible to argue that it solves the problem better than regulation, but, on the other hand, it leaves more chances for a technological shift at the later stages compared to the regulatory policy that creates opportunities for leaders to determine technological development. Moreover, even if the market outcome is not the best from short-term efficiency perspectives, industrial pluralism is able to be a basis for a future technological breakthrough.

We observe more innovations in those parts of telecommunications where regulator is less active, but the core, the physical layer, of the industry is changing gradually in sustaining, not disruptive, way of development of the technology. Regulation has locked-in the future development of the industry on the mainstream technology and eliminated alternatives. Meanwhile, the WiMAX story shows us that not only that concentration in telecommunications is not a necessary condition for the innovative development, but also that disruptive technologies are able to attract investments in this field from newcomers and weak players of the industry, putting the mainstream under the pressure of competition, and fostering innovations in their business. However, innovations require accessibility of the main resources and that might be achieved only if the resources are in the common domain. Even if WiMAX was not the technology that could benefit from this openness, it had chances to evolve to the version that could. The main advantage of the open access to the essential resources is that the openness makes easier the appearance of disruptive innovations, and regulation must facilitate this openness in order to promote the opportunities for creative destruction.

The alternative viewpoint might be that the process of technological change should be governed in public interests by public agencies because they have abilities to weigh costs and benefits of different technological regimes and choose more suitable direction for social interests. In fact, this is an alternative representation of the old discussion about virtues of "the invisible hand" and the opinion, like of Stiglitz (2001), that this hand "is simply not there", and the diversity of the theories of modern economics does not provide us any uniformity. However, even if we assume that the problem of regulatory capture is not relevant to the issue, and that the regulator is able to understand social interests and bases its actions on this understanding, we still cannot escape from the problems of epistemological limitations, transaction costs and information asymmetry, and, thus, we do not have reasons to believe that public agencies are able to govern the process of technological change better than market mechanisms.

The phenomenon of sunk costs has a deterring effect on the adoption of non-mainstream innovations by incumbents, while for potential new entrants this issue does not exist if they have not invested yet in currently presented technological solutions and they might be eager to jump into an alternative technological paradigm. However, if resources in the industry are under the total control of incumbents, then their decision about the use of such resources can 
not be free from the influence of the previous investments, i.e. the presence of sunk costs heavily affects the direction of technological change if the decision making is centralised in the hands of the main players. Therefore, if regulation contributes to such centralised decision making and if the outcome of the decision making is affected by the presence of sunk costs, then this contribution shapes the entire way of technological change. Meanwhile, active participation of newcomers in innovation activity may facilitate the process of creative destruction and, thereby, result not only in positive economic effects, but also in alleviation of socio-economic problems (see., e.g., an analysis of the impact of this process on income inequalities in Antonelli and Agnieszka 2016).

Nowadays the LTE camp analyses the possibility to use the technology in the unlicensed radio bands and considers that technology is able to be adopted by private entities as an analogy of Wi-Fi. The same was heard in 2004 - 2010 from the disruptors of the mainstream market, but now the ideas of the disruptive innovation have been transformed into the sustaining innovation of the orthodox part of the industry. Furthermore, now the regulation moves towards such experiments, but, again, this movement supports the mainstream. It shows that regulation is able to support evolution of established technologies and adjust itself to sustaining innovations, but if leaders win in battles of sustaining innovations and entrants have opportunities to beat incumbents when disruptive innovations emerge (Christensen 2006), then this is the regulatory regime that does not leave chances to change the landscape of the core of the industry but not the superiority of the leaders.

Acknowledgments The author is grateful to Ronald Leenes for helpful suggestions and discussion. The author would also like to thank an anonymous referee for many valuable comments.

Open Access This article is distributed under the terms of the Creative Commons Attribution 4.0 International License (http://creativecommons.org/licenses/by/4.0/), which permits unrestricted use, distribution, and reproduction in any medium, provided you give appropriate credit to the original author(s) and the source, provide a link to the Creative Commons license, and indicate if changes were made.

\section{References}

Antonelli C (1995) Localized Technological Change in the Network of Networks: the Interaction of Regulation and Technological Change in Telecommunications. Ind Corp Chang 4(4):737-754

Antonelli C (2007) Technological knowledge as an essential facility. J Evol Econ 17(4):451-471

Antonelli C, Agnieszka G (2016) Technological change, rent and income inequalities: a Schumpeterian approach. Technol Forecast Soc Change. doi:10.1016/j.techfore.2016.09.023

Baig R, Roca R, Freitag F, Navarro L (2015) guifi. net, a crowdsourced network infrastructure held in common. Comput Netw 90:150-165

Baker J (2010) Is WiMAX a failure in the UK? MuniWireless, June 21. http://muniwireless.com/2010/06/21/isWiMax-a-failure-in-the-uk/

Benkler Y (2002) Some economics of wireless communications. Harvard J Law Technol 16(1):25-83

Boldrin M, Levine DK (2008) Against intellectual monopoly. Cambridge University Press, Cambridge

Bower JL, Christensen CM (1995) Disruptive technologies: catching the wave. Harv Bus Rev 73:43-53

Brownsword R, Goodwin M (2012) Law and the technologies of the twenty-first century. Cambridge University Press, Cambridge

Brownsword R, Somsen H (2009) Law, innovation and technology: before we fast forward - a forum for debate. Law, Innov Technol 1(1):1-73

Butenko A, Larouche P (2015) Regulation for innovativeness or regulation of innovation? Law, Innov Technol 7(1):52-82

Canoy M, de Bijl P, Kemp R (2003) Access to telecommunications networks. TILEC Discussion Paper, No. DP 2003-007

Christensen CM (2006) The ongoing process of building a theory of disruption. J Prod Innov Manag 23(1):39-55 
Christensen CM, Raynor M (2003) The innovator's solution: creating and sustaining successful growth. Harvard Business Review Press

Christensen CM, Hatkoff C, Kula RI (2013) Disruptive innovation theory revisited: toward quantum innovation. The Off-White Papers, April 12. http://offwhitepapers.com/?p=21

Conti JP (2005) The long road to WiMAX [wireless MAN standard]. IEEE Rev 51(10):38-42

De Bijl Paul (2005) Structural separation and access in telecommunications markets. CESIFO Working Paper No. 1554. http://www.SSRN.com/abstract=843324

De Streel A, Larouche P (2015) disruptive innovation and competition policy enforcement. Note for the 2015 OECD Global Forum on Competition, October 20th. http://ssrn.com/abstract=2678890

Dogan SL, Lemley MA (2008) Antitrust law and regulatory gaming. Stanford Law \& Economics Olin Working Paper No. 367. http://ssrn.com/abstract=1287221

Fitchard K (2008) Intel's wireless dreams. Telephony 249(12):15-18

Gardiner B (2007) IDF: Intel CEO Says "Wimax Is Moving to Mainstream". WIRED, Sept. 18. http://www.wired.com/2007/09/idf-day-one-the/

Gilbert R (2006) Looking for Mr. Schumpeter: where are we in the competition-innovation debate? Innovation Policy and the Economy, vol. 6, edited by A. Jaffe, J. Lerner, and S. Stern, 159-215. The MIT Press

Govindarajan V, Kopalle PK (2006) The usefulness of measuring disruptiveness of innovations ex post in making ex ante predictions. J Prod Innov Manag 23:12-18

Grove AS (1996) Only the paranoid survive: how to exploit the crisis points that challenge every company and career. Currency Doubleday, New York

Grove AS (1998) Keynote speech presented at the annual meeting of the Academy of Management, San Diego, CA. August 9. http://www.intel.com/pressroom/archive/speeches/ag080998.htm

Higginbotham, Stacey (2010) Intel's losing big money on WiMAX. Giga Om, June 25. https://gigaom. com/2010/06/25/intels-bad-bet-on-wimax-pays-off-for-td-lte/

Intel (2005) Deploying license-exempt WiMAX solutions. white paper. Available at http://ecee.colorado. edu/ ecen4242/marko/WiMax/WiMax/WiMAXSolutions.pdf

Kushida KE (2015) The politics of commoditization in global ICT industries: a political economy explanation of the rise of apple, google, and industry disruptors. J Indust, Compet Trade 15:49-67

Larouche P (2007) Europe and investment in infrastructure with emphasis on electronic communications. TILEC Discussion paper, No. DP 2007-31

Lemley MA (2009) A cautious defense of intellectual oligopoly with fringe competition. Rev Law Econ 5(3): 1025-1035

Lemstra W, Voogt B, van Gorp N (2015) Measuring broadband in Europe: development of a market model and performance index using structural equations modelling. Telecommun Policy 39:253-268

Lessig L (2001) The future of ideas. Random House, New York

Lessig L (2006) Code: Version 2.0. New York. Basic Books

Lewan M (2005) Oväntat Qualcomm-köp skakar om mobilvärlden. Ny Teknik, August 12. http://www.nyteknik. se/digitalisering/ovantat-qualcomm-kop-skakar-om-mobilvarlden-6440830

Liebowitz SJ, Margolis SE (1995) Path dependence, lock-in, and history. J Law Econ Org 11:205-226

Machlup F (1958) An economic review of the patent system. study of the subcommittee on patents, trademarks and copyrights of the Committee on the Judiciary. 85th Congress. Washington D.C

MacKenzie D, Wajcman J (1999) The social shaping of technology, 2nd edn. Open University Press, Buckingham

Marchant GE, Allenby BR, Herkert JR (2011) The growing gap between emerging technologies and legal-ethical oversight: the pacing problem. International library of ethics, law and technology, vol. 7. Springer, Dordrecht

Melody WH (2012) Viewpoint: the closing of the liberalization Era in European Telecommunication. Compet Reg Netw Indus 13:218-235

Merges RP (2000) Intellectual property rights and the new institutional economics, 53 Vand. L. Rev. 1857

Milgrom P, Levin J, Eilat A (2011) The case for unlicensed spectrum, Oct. 12. at http://www.stanford. edu/ jdlevin/Papers/UnlicensedSpectrum.pdf

OECD (2006) The implications of WiMAX for competition and regulation. OECD Digital Economy Papers, No 108, OECD Publishing. doi: 10.1787/231618416012

Posner RA (2005) Intellectual property: the law and economics approach. J Econ Perspect 19(2):57-73

Roodaki M, Raahemifar K, Raahemi B (2014) Analysis of quality of services in LTE and mobile WiMAX. Comput Elect Eng 40(5):1508-1523

Sah RK, Stiglitz JE (1986) The architecture of economic systems: hierarchies and polyarchies. Am Econ Rev 76(4):716-727

Scotchmer S (1991) Standing on the shoulders of giants: cumulative research and the patent law. J Econ Perspect 5(1):29-41

Seo D (2013) Evolution and standardization of mobile communications technology. IGI Global 
Shelanski H (2013) Information, innovation, and competition policy for the internet. Univ Pennsylvania Law Rev 161:1663-1705

Staple G, Werbach K (2004) The end of spectrum scarcity. IEEE Spectr 41(3):48-52

Stiglitz JE (2001) Nobel prize lecture: information and the change in the paradigm in economics. Dec. 8

Vos E (2010) Another one bites the dust: Worldmax shuts WiMAX network in Amsterdam. MuniWireless, June 22. http://muniwireless.com/2010/06/22/worldmax-shuts-WiMax-in-amsterdam/

Wei H-Y, Ganguly S, Izmailov R, Zygmunt JH (2005) Interference-aware IEEE 802.16 WiMax mesh networks. In 2005 I.E. 61st Vehicular Technology Conference, vol. 5: 3102-3106

Weil HB (2009) Why markets make mistakes. MIT Sloan Research Paper No. 4745-09. August 10. Available at SSRN: http://ssrn.com/abstract=1446802

Werbach K (2001) Open spectrum: the paradise of the commons. Esther Dyson's Monthly Report Release 1.0 19(10): $1-30$

Werbach K (2004) Radio revolution: the coming age of unlicensed wireless. New America Foundation

WiMAX Forum (2004) Regulatory position and goals of the WiMAX Forum. Version June 16, 2004. Available through Internet archive http://www.wimaxforum.org/technology/downloads/WiMax_Forum_Regulatory_ Whitepaper_v08092004.pdf

Wu T (2006) Intellectual property, innovation, and decentralised decision. Virginia Law Rev 92:101-127

Yarali A, Mbula B, Tumula A (2007) WiMAX: a key to bridging the digital divide. Southeast Con Proc IEEE. doi:10.1109/SECON.2007.342874

Yoo CS (2014) US vs. European Broadband Deployment: What Do the Data Say? University of Pennsylvania, Inst for Law \& Econ Research Paper No. 14-35. Available at SSRN: http://ssrn.com/abstract=2510854 